\title{
Teaching Academic Literacy Using Popular Science Texts: A Case Study
}

\begin{abstract}
Developing strong communicative ability amongst science graduates, especially in science communication, has been included as a fundamental learning outcome in some science degree programmes. This article focuses on a compulsory academic literacy course for firstlevel undergraduates that is aimed at developing academic reading and writing skills beyond the considerations of deficit language proficiency. It straddles the general, discipline-specific dichotomy in the skills aimed at, course content, and materials used. It targets two core science communication skills in addition to general academic literacy. In addition, the content and materials consist of popular science and media texts to facilitate the discussion of scientific ideas made accessible to the lay reader. It investigates course effectiveness on developing coherence in students' writing. Results obtained suggest that indicators of coherence, especially in the integration of source ideas and writers' proposition and the logical progression of textual ideas, are correlated to the difference in improved essay scores.
\end{abstract}

\section{KEYWORDS}

academic literacy, popular science, coherence, undergraduate, science communication

\section{INTRODUCTION}

The need for strong communicative competence amongst undergraduates to meet the rigorous academic writing demands of a tertiary education has been widely discussed. Communicative competence ranks high among the list of top-10 soft skills that executives emphasise as important in ensuring long term job success in the 21st-century workplace (Robles, 2012). Robles recommends a stronger emphasis on these soft skills in the early stages of students' academic paths to prepare them early for their professional careers.

This need for strong communicative competence, and especially academic literacy, amongst undergraduates is pervasive in many English medium universities, where it is common to find enrolled students whose first language is not English. Murray and Nallaya (2014) describe a situation where the possible demography of university students is such that a sizeable percentage of the students does not have the requisite level of English proficiency to meet the academic literacy demands needed for successful learning. Increasingly, there have been observations of "home students" (presumably, local students who are native speakers of English in English medium universities) who are similarly challenged with academic writing demands and their related tasks, including the need to think critically, read, and 
write logical argumentations with clear positions on respective discipline-related issues. Hathaway (2015) points out the need to include all students in such programmes irrespective of their linguistic backgrounds as these courses make meaningful preparation for students' current and subsequent stages of learning and are not focused on correcting deficient language proficiency. She details the conceptualisation and evaluation of a compulsory writing support effort in the United Kingdom, which forms part of the core curriculum of the undergraduate programme.

Universities around the world adopt varied approaches to support and develop the academic literacy needs of undergraduates. One line of approach amongst some U.S. universities is writing across the curriculum, which prioritises the learning of writing skills in the first year within first-year composition classes. Writing across the curriculum fundamentally proposes that both knowledge and language are intertwined so that the knowledge is constructed as communication of the content is engaged. Subsequently, the Writing In the Discipline (WID) courses were designed to develop students' disciplinary writing skills within the context of a community that defines and uses the conventions of the discipline. As such, there are the consultation and collaborative models (Emerson, MacKay, MacKay, \& Funnell, 2006) that guide the different degrees of team effort between writing specialists and faculty lecturers in providing communication support to WID courses.

In some U.K. universities, several factors including the unprecedented expansion since the mid1980 s, the modularisation of programmes and the attraction of globalised education to international students exacted institutional responses in the form of study skills and English language support (Ganobcsik-Williams, 2006). Approaches to the teaching of writing are admittedly diverse and underpinned by differentiated views of what academic literacy means. However, since the mid-1990s, writing research in the United Kingdom has been evolving the view that writing cannot be taught in a decontextualised manner apart from the knowledge acquisition process - that issues of language and learning need to be incorporated into the curriculum. This view underlines the academic literacies approach, which recognizes the complexities of writing beyond the learning of a set of accepted conventions. In fact, the writing process is a negotiation process with implications for how meaning is made and how identity is shaped as the nature of knowledge is contested. The negotiation of meanings and identity is not confined to writing development but affects teaching and learning issues in general. As a result, current writing support in some U.K. universities commonly stems from within the discipline with varied models of embedding the learning of writing skills within the process of developing disciplinary knowledge (Hathaway, 2015; Murray \& Nallaya, 2014; Wingate, 2012).

Harris (2016) details the provision of English-language support programs in some Australian universities such as English-Language Proficiency (ELP), which involves both the international students as well as the "domestic cohort" where there was observed "decline in written expression" amongst graduates. According to Harris, varied policies were evolved in Australian universities to address undergraduates ELP with the 2008 Review of Higher Education (Bradley, Noonan, Nugent, \& Scales, 2008; Harris, 2016, p. 291) emphasising the need to integrate ELP issues within the core curriculum. Initiatives to embed English-language skills within content subjects were described as "best practices" to support ELP in Australia, South Africa, and the United Kingdom since the early 2000s (Harris, 2016, p. 291). Arkoudis, Baik, and Richardson (2012) also provides an overview of a range of literacy programmes embedded in content courses that are conducted along with other standalone writing and communication courses to meet diverse writing competencies. 
In the context of a science undergraduate programme where this study is situated, the need for strong communication skills is well recognized. The Faculty of Science and the Centre for English Language Communication co-developed a new course, Exploring Science Communication through Popular Science, in 2013. The course encompasses the development of all science first-year undergraduates' communication competence in a compulsory science writing course that introduces students to academic literacies essential to the construction of meaning for academic purposes. It enables students to read science-related publications critically and to articulate scientific arguments and perspectives coherently both in writing and orally. Learning such academic literacy skills involves what Hathaway (2015) describes as the epistemological, cultural, and linguistic aspects as undergraduates learn to participate in new knowledge communities, each having their conventional ways of constructing and expressing knowledge and meaning.

Essentially, the course draws from the Academic Literacies approach (Lea, 2004) which prioritises the learning of a new academic culture in the process of learning to write academically. It is more about learning to negotiate meaning in the context of a community of users as well as developing an identity in the process than about learning to write in a right way from a learners' deficit point of reference. The approach emphasises the need for students to engage with the process of writing, and to explore, dialogue, reflect, and actively develop a sense of identity and voice in relation to the texts being written.

The course centeres on the teaching of reading, writing, and oral communication competence for science students. Central to the course is the aim of facilitating clear and coherent writing skills in the argumentative genre that requires critical thinking and reading of professional science materials in developing a stance toward a science related issue. The four student learning outcomes of the teaching and learning assessment are as follows:

1. Development of the habit of reading, especially in science-related topics

2. Enhancement of their ability to critically question published scientific information.

3. Enhancement of their ability to articulate opinions and perspectives.

4. Development of coherence in their writing and oral communication.

The ability to communicate scientific inquiries, ideas, procedures, theories, and scientific understandings coherently under different contexts is one of the four learning objectives. Out of MercerMapstone and Kuchel's (2015) 12 science-communication skills, two key skills are prioritized, given practical constraints working against the teaching all 12 skills: (1) identify and understand a suitable target audience, and (2) use language that is appropriate for the target audience. Essentially, these two important generic skills describe competence in writing coherently as knowing one's audience and presenting knowledge using the appropriate register of language for the academic audience. These are fundamentals in effective communication.

This study focuses on the attainment of coherence (outcome 4) as partially indicating the attainment of reading habit and critical evaluation of scientific information (outcomes 1-3). Competence in coherence may be indicative of the writers' awareness and use of critical reading and writing processes and strategies as they orientate textual elements to match readers' reading skills and topical knowledge level. A coherent writer is a competent reader who reads critically as well. Crossley and McNamara (2010) explain that coherence as the understanding that the reader derives from the text, which may be more or 
less coherent depending on a number of factors, such as prior knowledge and reading skill. Thus, the close connection between reading skill and prior knowledge and the concept of coherence helps explain why the study views competence in coherence as partially reflective of the achievement of other course outcomes such as competencies in reading and analysing ideas.

Coherence, as conceptualised in this study, draws on competencies in reading, analysing and responding with a critical stance to scientific ideas. Coherence, a basic dimension of written discourse has both local and global level manifestations. At the local level, it involves the transition from sentence to sentence or the relations between adjacent propositions in texts while global level coherence refers to how larger segments of texts (e.g., paragraphs) are related (Bamberg, 1983). Text comprehension requires the effective processing of both local and global level coherence. Coherence has been variously investigated as logical relations, relations of coherence, sentence roles, rhetorical predicates, and ideas coordination (Concha \& Paratore, 2011). The various interpretations of the construct have also meant that it has been operationally challenging to design assessment tools to ascertain the coherence quality of a text. Knoch (2007) cites a range of criticisms of coherence tools being vague and not affording necessary specifications for decision making in rating to other criticisms against the extremely fragmented nature of such tools that make the reading of meaning almost impossible. However, it seems that Hoey (1991, quoted in Knoch 2007) was able to show that raters could reach a consensus of the coherence quality of texts despite the vague nature of these assessment tools.

Lee (2002) identifies the following features as characteristic of a coherent text:

a. The presence of a macrostructure that reflects the functions and purpose of the text whether it is narrative or argumentative.

b. The presence of an information structure that directs readers in the organization of information and topic development.

c. Propositions in the text are related through strategies of justification or exemplification such that the underlying connectedness of the content is evident.

d. The presence of cohesive devices to connect ideas at the sentence level.

e. The presence of metadiscourse markers to guide readers in their comprehension and evaluation of text.

Translations of such features into an analytic rubric for grading require the itemisation of elements that contribute to that sense of coherence. Todd, Thienpermpool, and Keyuravong (2004) suggest that the discourse-level descriptions such as the following are used in analytic scoring rubrics for coherence:

1. well organised

2. exhibit logical sequencing

3. be cohesive

4. exhibit a clear progression of ideas well linked

5. provide clear and consistent evidence of the ability to produce organised coherent and cohesive discourse 
These descriptions of coherence shape the design of the analytic rubric used to grade the essays in this study (Table S1). In the rubric, coherence is exemplified by the construct of organisation (the other two being content and language). The alignment between the rubric elements and the concept of coherence adopted is reflected in Table 1.

Table 1. Alignment of rubric elements to the assessment of coherence

\begin{tabular}{|l|l|}
\hline $\begin{array}{l}\text { RUBRIC (ORGANISATION ELEMENT) } \\
\text { conclusion with the position reinforced }\end{array}$ & $\begin{array}{l}\text { RUBRIC ELEMENTS ALIGNING WITH THE CONCEPT OF COHERENCE } \\
\text { argumentative purpose of the text. The conclusion } \\
\text { reiterates that position maintained. Consistency in } \\
\text { introduction and conclusion points to global coherence } \\
\text { achieved. }\end{array}$ \\
\hline Functions of source ideas discernible & $\begin{array}{l}\text { Rhetorical functions of citations are clear so that source } \\
\text { texts provide evidence, definition, exemplification, or } \\
\text { explanation that support the connectedness in arguments } \\
\text { coherently. }\end{array}$ \\
\hline $\begin{array}{l}\text { Effective integration of source ideas and author's } \\
\text { ideas }\end{array}$ & $\begin{array}{l}\text { Coordination and logical flow of ideas between source texts } \\
\text { and writer's ideas are smoothly integrated, using various } \\
\text { linguistic structures. }\end{array}$ \\
\hline $\begin{array}{l}\text { Logical progression of ideas between sentences } \\
\text { between paragraphs }\end{array}$ & $\begin{array}{l}\text { Local coherence of ideas is indicated by various cohesive } \\
\text { devices and signposts used between clauses and sentences. }\end{array}$ \\
\hline & $\begin{array}{l}\text { Construction of logical consistency between the thesis } \\
\text { statement and the subsequent sentences in each paragraph } \\
\text { so that on the whole, the paragraph makes a coherent point. } \\
\text { Between paragraphs, the development and elaboration of } \\
\text { key ideas are well connected through various meta- } \\
\text { discourse items. }\end{array}$ \\
\hline
\end{tabular}

This study investigates students' academic literacy skills as exemplified by their competence in constructing coherent argumentative essays in a science communication skills course. The study also informs us on the degree of effectiveness of the course. Furthermore, it is the case that curriculum development needs to be informed by investigations into baseline evidence of course effectiveness in the evaluation process. The study seeks answers to Hutching's "what works?" question to gain insights into the effectiveness of the course. In terms of Hubball and Clarke's (2010) programme evaluation framework, this investigation is situated within the Educational Initiative Completion (E-3) phase, where the focus is on the results of a curricular initiative's summative evaluation. It draws in elements of action research methodology that engage both theory and practice in systematic and cyclical processes of inquiry, including hypothesis testing, planning, observing, analysis, and action (Hubball \& Burt, 2007). Data included quantitative scores of students' writing. Analyses of these data were conducted with the aim of understanding the possible impact of the course and subsequent actions of course review and reshaping. 


\section{METHODS}

\section{The course}

The course, Exploring Science Communication through Popular Science, aims to develop students' communication abilities through reading, classroom discussion, summary writing, essay writing, and oral presentation activities. Parkinson and Adendorff (2004) recommend the use of popular science articles for teaching scientific literacy, although they identified clear differences between the popular science genre and the research article and textbook genres which are more similar to each other. One major difference between popular science and the research article and textbook genres is the way in which knowledge is presented as provisional rather than as facts accepted by the scientific community. As explained by Parkinson and Adendorff (2004), the narrative nature of popular science depicts knowledge as yet-to-be-endorsed claims attributable to research results in a genre that is high on the interpersonal scale and prioritises what people think, say, and feel about these knowledge claims. It is common to find information in popular science genres configured as a debate between two opposing voices rather than couched as established knowledge claims. This feature facilitates the reading, thinking, and critical response to knowledge presented in the current course; in fact, the discursive nature of these texts is leveraged to generate the necessary discussion and analysis of targeted notions to enable further written responses to these claims that come across as provisional. Also, as pointed out by Afonso and Gilbert (2013), popular science texts focused on chemistry enable the informal engagement of chemistry knowledge where the focus on abstract concepts that are detached from technological applications and implications is minimized. Engagement with these materials might present the students with rich examples of the essentials of science communication - of how science can be presented to facilitate the informal acquisition of scientific knowledge and thus, science education. The aim of the course is not to train science communication specialists or science journalists but to develop students' awareness and foundational skills in effectively communicating science to the educated audience. This is a 48-hour course taught over 13 weeks with two, two-hour sectional teaching per week. There are 18 students per class to ensure appropriate student-tutor ratio for the discussion of writing drafts at different stages of the process.

The collaborative approach outlined by Blake and Pates (2010), between faculty and language centre staff that involves team teaching, presented various challenges in the current context of inquiry. As such, a level of cooperation between the science faculty content staff and English-language faculty enables information collection about the science discipline genres, text types, conventions, and academic practices. Cooperation also comes in the form of the selection of five popular science books and news media texts assigned to the course. The language staff teach academic literacy skills using disciplinerelated discourse, texts, and practices in the classroom. Popular science texts in this course were carefully selected with consideration of different student interests, abilities, and quality of writing. Representing the five domain areas of science-physics, life sciences, mathematics, chemistry, and statistics - the readings are the following:

1. Stephen Hawking, A Brief History of Time: From the Big Bang to Black Holes.

2. Peter Pringle, Food Inc.: Mendel to Monsanto-The Promises and Perils of the Biotech Harvest

3. Marcus du Sautoy, The Music of the Primes: Searching to Solve the Greatest Mystery in Mathematics 
4. Penny Le Couteur and Jay Burreson, Napoleon's Buttons: 17 Molecules that Changed History

5. Judith M. Tanur, Statistics-A Guide to the Unknown

The science faulty staff also remained as partners for clarification of concepts and ideas within the texts as well as a source of feedback on the types of materials and activities developed from these texts. The use of popular science texts in fact facilitated the role of the language staff, as science knowledge in these texts is more accessible than in professional academic publications. Thus, it partially resolves the challenge of nonscientists engaging with the discursive practices of scientific discourse (Afonso \& Gilbert, 2013).

The embedding of academic literacy skills takes the form of student engagement with science related texts and topics. The course content revolves around controversial issues raised in popular science and media texts that present the springboard for small-group discussion pedagogy. Soules et al. (2014) describe the embedding of multiple academic literacies in a science, technology, engineering, and mathematics (or STEM) curriculum. Reading and writing literacies form an important component of the programme, the authors explain, as effective reading strategies for texts with higher levels of difficulties may need to be developed for students who may have mastered basic reading skills. Based on the work of Sweet (2000), the authors highlight the active nature of reading that involves the construction of meaning before, during, and after reading science texts. The awareness of the use of metacognitive strategies, including the activation of schematic knowledge to construct new meaning and to connect prior and new knowledge all contribute to the reading comprehension process. The teaching of writing competence would then entail the teaching of effective reading skills to construct relevant scientific knowledge. These interlocking processes of reading, critical thinking strategies, the constructing of meaning and the connecting of knowledge are metacognitive skills that help students learn successfully in a college physics class (Bullock, 2006).

Hathaway (2015) cites three domains of learning that show the kinds of cultural shifts that undergraduates experience in developing their academic identity: referencing, critical thinking, and language. Referencing transcends beyond the technicality of citation and includes considerations of the "contested nature of knowledge" (Parkinson \& Adendorff, 2004) that requires sources to be critically engaged with. Questions of what to cite and how to cite sources that function in rhetorically effective arguments are related to epistemological issues of how knowledge is contested and constructed in texts. Thus, such referencing activities also involve critical reading and thinking which help students develop that academic disposition in the context of scientific issues. The aspect of learning academic discourse skills is not merely about learning a set of writing conventions. Instead, academic communities and their ways of knowing, valuing and saying are all related so that learning the ways of expressing the constructed meaning also involves learning how knowledge is constructed. On the basis of these perspectives on the connections between reading and writing, this course aims at achieving the previously stated student learning outcomes.

Table 2 presents a sample of the course organisation that connects classroom content, pedagogy, and learning outcomes. It shows how a chapter in the physics book provides the platform to scaffold the attainment of student outcomes listed. Course assessment tasks are presented in Table 3. 
Table 2. Sample of scaffolding activities using popular science texts

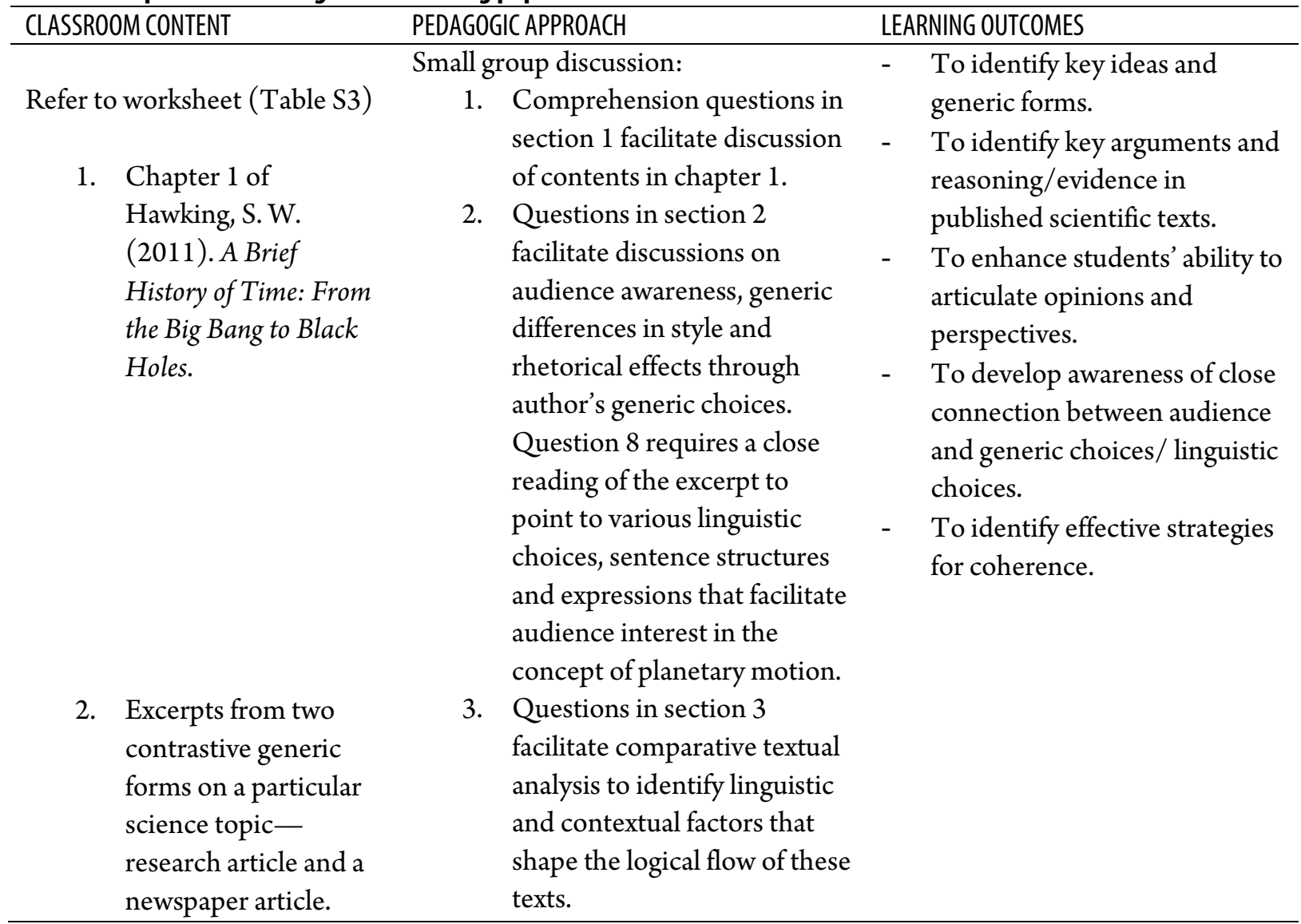

Table 3. Series of continual assessments in the course

\begin{tabular}{lll}
\hline ASSIGNMENTS & WEIGHTING \\
\hline 1. Synthesis writing (500-600 words) & $10 \%$ & \\
2. Group presentations (\#1-\#2) & $15 \%$ & \\
3. Argumentative essay (1500-1800 words) & $30 \%$ & Draft 1 \\
& & Draft 2 (20\%) \\
& & Final draft (10\%) \\
4. Peer review report & $6 \%$ & \\
5. Individual oral presentation & $20 \%$ & \\
6. Reflections (\#1-\#2) & $9 \%$ & \\
7. Class participation: discussion (group and online discussion), feedback, & $10 \%$ & \\
e-tutorial participation & & \\
\hline
\end{tabular}

\section{Study subjects}

Based on their pre-university credentials, the first year students are broadly categorised as high school graduates who sat for the General Certificate of Education Advanced Level (GCE A- level), International Baccalaureate, high school diploma, polytechnic diploma, and foreign- equivalent examinations. First-year students who sat for the GCE A-level examination represent the majority of the 
student population in the faculty. Taking into consideration the limited sample size from the other four groups of students and the large heterogeneity among different groups, this study focused on the GCE A-Level first-year students who read the course in the academic year 2013-2014. The course has been offered to all first-year science students from five departments and two programs (considered as seven majors henceforth) since the first semester of academic year 2013-2014, and it is a graduation requirement for all science undergraduates.

\section{Study design}

\section{Essay rating}

The data set consists of 600 essays ( 300 pre-course and 300 post-course) collected from 300 students longitudinally. 300 out of 330 essays were selected as the other 30 essays were either not submitted, too short (below 400 words) or too long (above 950 words). The pre- and post-course writing tasks are the same. The essay structure and requirements mirror that of the Argumentative essay assignment in the course assessment (Table 2). The task consists of an argumentative writing prompt: "Read Texts A-C carefully and write an essay of about 600-700 words to answer the question: Do you support the use of aquaculture as a sustainable method to meet the global demand for food? State your position clearly and use the information from the three texts to support your answer." Texts A, B, and C all concern aquaculture and its related sustainability issues. The pre- course essays were completed one week before the start of the writing course while the post- course essays were collected three months after the completion of the course (during the term break of the subsequent semester). Students completed both essays outside of class time but within a specified time frame and submitted their work through the university's learning management system. Students were assessed via 13 rubric elements (Table 51), each rated on a five-point Likert-type scale. Rubric elements were divided into three category aggregates: content (four elements), organisation (five elements), and language (four elements).

\section{Reliability measures}

Several measures were taken to minimise inconsistent rating of essays amongst the group of seven raters. Firstly, rater training was conducted on three essays to derive a better sense of how the rubrics should be used. The rubrics were developed for the scoring of the argumentative essay (Table S1). Three essays representing the high, mid, and low level of grades respectively were adopted as reference during the rater training session. The scripts and rubrics were given to raters before the training session. The session was used to discuss ratings on the three components-content, organization, and language - of the three scripts.

As a second level of reliability measure, the Multifaceted Rasch Model (MFRM) was used to minimise rater inconsistency on the scores. MFRM is an extension of the Rasch model that is used for assessments with multiple facets. The theory underlying this measurement model is that the probability of a certain performance being given a particular score can be seen as a function of the examinee's ability and several other facets of the scoring situation, such as the severity of the rater, the difficulty of the task, and the threshold of difficulty between the points on the scale. When we estimate these facets, we can arrive at a more objective estimate of the examinee's ability in the quality being tested given that the model assumes specific objectivity (i.e., the property that asserts comparison of two test takers should be 
independent of the difficulty of items they answer or the severity of raters who rate them [Rasch, 1993]). A four-facet Rasch model is expressed as follows:

$\log \left(\mathrm{P}_{\mathrm{nijk}} P_{n i j(k-1)}\right)=B_{n^{-}} C_{j}-D_{i}-F_{k}$, where:

$P_{\mathrm{nijk}}$ is the probability of essay $\mathrm{n}$ being rated $\mathrm{k}$ by Rater $\mathrm{j}$,

$P_{\mathrm{nij}(\mathrm{k}-1)}$ is the probability of essay $\mathrm{n}$ being rated $\mathrm{k}-1$ by Rater $\mathrm{j}$,

$B_{\mathrm{n}}$ is the ability of the student as reflected in the quality of the essay, $\mathrm{C}_{\mathrm{i}}$ is the severity of the

rater, $D_{i}$ is the difficulty of the item and

$F_{\mathrm{k}}$ is the difficulty of the rating scale step relative to the previous step.

The MFRM simultaneously and independently analyses the impact of different facets - student, rater, item - and calibrates the impact into one common log-linear scale (logit scale). One of the significant measures is rater severity, which refers to a rater's tendency to assign lower ratings than other raters for the same examinees. The MFRM maps harsh to lenient rating behaviour on a logit scale between -5 (absolutely harsh) to 5 (absolutely lenient) so that raters re-identified relative to each other's level of rater severity. Another useful measure is the examinees' fair scores which are scores derived independently of the variation in judge severity. It gives a fair measure of the students' performancemeasures that would be obtained if raters were equally lenient. The difference between the fair and actual scores obtained is the residual measure for each examinee. According to Linacre (1994), an "inspection of the residual differences between the observed and expected ratings enables unexpectedly harsh ratings to be identified" (p. 12). The residual measure is helpful for the selection of scripts to review, especially when they fall beyond a tolerable range of difference.

The first set of 600 score points were subject to a MFRM analysis to identify possible areas of misfits in ratings whereby students are not scored fairly due to rater, rather than competency, factors. One such indicator of rater factor can be seen in the measure of the residual generated, which measures the difference between the actual observed scores and expected values of each script (Bond \& Fox, 2007). On the basis of the indicator generated, a total of 64 scripts was identified as having at least one or more items being rated in an unexpected manner and therefore needed review. Given resource constraints, a total of 100 items with the highest residual measures were reviewed. A recommended measure to manage these inconsistently rated scripts is to have a third experienced rater who has the rater severity measure relatively close to the mean severity of zero and mean-square residuals between 0.5 and 1.5 to rescore the scripts (Lunz \& Linacre, 1998). Those 100 items with high residual values ranging from -2.4 to 1.8 were rescored by a third rater who was identified by the earlier MFRM analysis to be the most consistent rater amongst the seven raters. A new set of scores was generated for this set of scripts.

\section{Statistical test of significant difference}

The assumption of normality and subsequent use of parametric statistics in Likert-type scales are often empirical and debatable. Normality of students' scores (total and category aggregate) were first checked with frequency distribution histograms and D'Agostino and Pearson normality tests, both performed using Graphpad Prism 6 (San Diego, CA). The pre-course score showed slight negative skew and failed the normality test $\left(\mathrm{K}^{2}=7.148, \mathrm{p}=0.0280\right)$, while the post- course score showed slight asymmetry but passed the normality test $\left(\mathrm{K}^{2}=1.999, \mathrm{p}=0.3680\right)$ (Figure $\mathrm{Si}$ ). Similar deviation from normality was observed within the content, organisation, and language category aggregates. As such, nonparametric paired Wilcoxon signed-rank tests were performed to evaluate the students' total scores, as well as within 


\section{RESULTS}

\section{Quantitative ratings}

The median total score (interquartile range) at the start and end of the course were 38 (34-45) and 41 (36-47) respectively. A paired Wilcoxon test showed an overall significant difference in the students' scores after completion of the course $(\mathrm{p}<0.0001)$, highlighting an improvement in the students' writing. Further Wilcoxon tests revealed significant difference in all 3 category aggregates of content, organisation, and language, with the greatest improvement in terms of organisation in writing (Figure 1).

\section{Figure 1. Scores across three major categories (content, organisation, and language)}

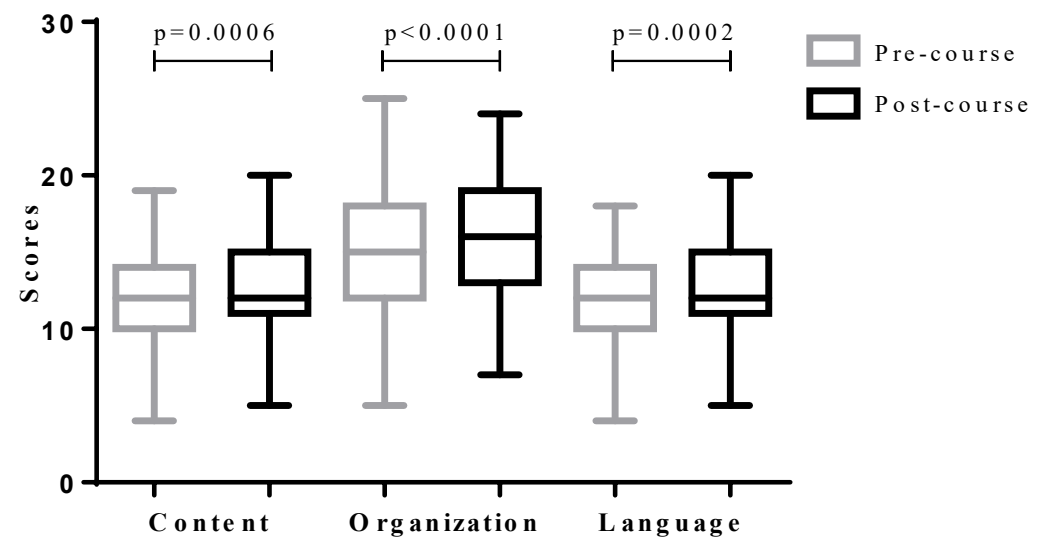

Scores across three major categories (content, organisation, and language) are represented in box and whiskers plot. Paired Wilcoxon tests showed significant differences between pre- and post-course scores of students in Content (median difference $=0.5, \mathrm{p}=0.0006$ ), Organization (median difference $=1.5$, $\mathrm{p}<0.0001$ ), and Language (median difference $=0.5, \mathrm{p}=0.0002$ ) at overall significance level of 0.05 .

\section{Qualitative observations}

Qualitative observations of a sampling of some essays attest to aspects of improvement indicated by the quantitative statistical results. Amongst the 10 essays with the biggest improvement in organisation, nine of the pre-essays showed no use of source texts with one essay showing improper use of one instance of an uncited source. The corresponding post-essays cited source texts and presented differentiated ideas.

A comparison of three pairs of pre- and post-essays' excerpts (Table S2) shows some interesting changes that indicate, possibly, the writers' better strategies for presenting ideas coherently at the postessay than they employed at the pre-essay stages. In Table S2, examples la, $2 a$ a, and 3a present excerpts from the pre-essays, while $\mathrm{lb}, 2 \mathrm{~b}$, and $3 \mathrm{~b}$ present those from post-essays.

With reference to the attainment of strategies outlined in the organisation element of the rubric for coherence in introductions, example 1a presents the topic that is being discussed (sentence 4) rather than the writer's position on the issue (see example $1 \mathrm{~b}$, sentence 6 ). Example $1 \mathrm{~b}$ shows more indications of the use of sub-skills in the rubrics; for example, example $1 \mathrm{~b}$ provides two logical supports for the writer's 
position on using aquaculture as a method for food supply.

In terms of the well-formedness of the introduction, the background provided in example la represents one perspective, which is the writer's perspective. The logical links from questions asked (sentences 1 and 2) to statement of issue (sentence 4) has to be made by the reader as sentence 3 does not indicate if the solution through technology has been successful. As such, readers would have to logically deduce that the solutions have not been too successful and thus, there is a need to pursue the issue of sustainable food supply further. In contrast, example $1 \mathrm{~b}$ provides a background to the issue that is substantiated by source texts at relevant junctures (sentences 1 and 4 ) so that the functions of sources used are clear. Source voice, general viewpoints (sentence 2 ) and the writer's perspectives are differentiated clearly so that the writer's position, which is in opposition to "valid concerns" (sentence 6) are logically developed and clearly stated.

With reference to example 2, the framing of perspectives in terms of an argumentative stance is more poignant in $2 b$ than $2 a$. The explicit framing (italicized portions, example $2 b$ ) of a contrastive stance on the issue enhances the logical connection of ideas and strengthens the persuasive thread of idea development (points 8 and 9 in the rubric, Table S1). The writer's position on the issue and the relevant reasons and analogy used are labelled and differentiated from other general sources of voice. The use of a concessive structure (sentence 7, "although...") again intensifies the argumentative stance so that the coherent flow of point versus rebuttal develops. Additionally, the use of suitably hedged items (underlined in example 2b) helps signal views that are to be argued against (sentences 3,4) as these views are temporarily conceded to before being rebutted. Such signaling clarifies the cohesive flow of ideas. Example 3 shows improvement in coherence in terms of the writer's engagement with source use, orientation of the development of source, and his or her own views for a coherent paragraph. In example $3 a$, the writer plunged into pundits' criticism against aquaculture without a context for the critical view. In example $3 b$, a series of source ideas regarding the usefulness of aquaculture (sentences 1-4), including the writer's evaluation of these source ideas (sentence 2, Sachs asserts rightly and sentence 5) are presented to provide a context and reasons that lead to a contrastive point of view from the pundits and their critical views on aquaculture. Sentences 9 to 13 then present the writer's stance on the potential benefits and the need for aquaculture not to be lightly dismissed, thus providing the resolution to the contrastive source voices.

\section{DISCUSSION}

The development of reading and writing skills in this study is embedded in disciplinary content in the sense that students were engaging with scientific content in popular science texts. Wingate (2012) argues that the analysis of discipline-specific texts is the best starting point for the teaching and learning of academic writing, and that students will be more willing to take a critical perspective when they are able to understand and control disciplinary discourses. The development of coherence skills in this study subsumes the development of the ability to reason and rationalise ideas in sources, explain reasoning, report facts, engage with knowledge claims made by other writers and communicate the essence of one's position on issues discussed in an organised manner. Woodward-Kron (2009, p. 165) demonstrates how native English language students' choice and range of lexico-grammatical items widened as students' disciplinary knowledge developed. A firmer grasp of lexico-grammatical items facilitated clear reasoning, reporting of knowledge claims and essentially, improved engagement with disciplinary knowledge and practices. 
Immersion into the lexico-grammatical choices, format and discourse features within the popular science genre provides that platform for interrogating textual forms to understand how disciplinary knowledge is rhetorically presented coherently and clearly to the audience. Close engagement with linguistic and discourse choices used in these texts and subsequent analysis and reflection on their strategic use inform the learners on effective academic communication strategies they may adopt.

This embedding of reading and writing skills in science content is similar to the experience of Soules et al. (2014) who reported on the embedding of multiliteracies in STEM courses. Amongst the other literacies aimed at, the authors cite positive student experience with students' engagement with reading strategies instruction, writing to learn exercises and writing as a process pedagogy in the science class. The authors maintained their belief that reading and oral or written explanations are keys to "ensuring that STEM students engage fully with content to develop the strongest possible understanding." In the current study, the positive improvement in grading is underscored by students' perception that the various reading and writing activities to improve academic literacy made them more confident writers (see Zhang et al., 2017 for students' perception of this course). Essentially, majority agreed or strongly agreed that the activities helped them to become better communicators. The students' positive perceptions result from classroom activities which demonstrate reading processes for various levels of comprehension including inferential and analytical skills do help advanced readers to gain affirmation of their own reading strategies. In particular, activities involving the annotation of ideas that surface connections and dissensions amongst propositions and the engagement with linguistic choices to signal these intertextual connections help students understand how coherence can be achieved as conversations on ideas are prevalent even in texts.

Other subskills contributing to coherent writing also showed improvement as students scored better with the way in which they use sources and their evaluation of source perspectives engaged. Thompson, Morton, and Storch (2013) raise the challenge of effective source selection and use amongst first year undergraduates. With regard to source use in the current study, students' writing showed improvement in how they used sources for various discernible purposes and how they were able to integrate source voice and authorial voice and yet differentiate them as shown in the qualitative analysis above. Similarly, Thompson et al. (2013) show how students move from confining the use of sources just to support their own position to one where they recognise the need for alternative perspectives from sources in their argumentation and the engagement of dialectal reasoning common in academic writing. They felt better able to evaluate and incorporate a broader range of source texts with proper citations. Additionally, qualitative data supported the process of students' confidence growth as they learn to develop their own voice and position (Zhang et al., 2017). A few students saw themselves as emergent writers as they realise the need and their potential ability to critically discuss, critique and contribute to authoritative ideas.

Mubarak, Hamzah, and Radjab (2013) studied cohesion and coherence development amongst fourth year students' argumentative essays. Of interest to this study is the area of coherence which may be achieved through effective language strategies such as repetition of key nouns, the use of pronouns to refer to key nouns and transitional devices. Furthermore, coherence is also achieved through the logical arrangement of sentences, including chronological order, logical division and order of importance. Their study found that the fourth-year essays were rather low in students' average scores in building both 
cohesion and coherence, with the former being the weaker ability. The current study however, found a significant improvement in students' grades in the category aggregate of organisation, indicating that the post-essays show improvement in the logical thread of argumentation.

One area of course improvement could be the level of science faculty involvement in the course. It could move towards Blake and Pate's (2010) team-teaching level, where content lecturers teach alongside language teachers. In a team-teaching setup, the faculty content lecturer draws on his/her disciplinary knowledge in the teaching of writing and contextualising the teaching of a sub-genre by reference to specific assignments. The language teachers support the faculty content lecturer with the details of teaching writing including the design of teaching materials and assessment tasks appropriate for the discipline. The content lecturer can relate to the students as insiders within the discipline. As Tapp (2015) explains, a community is defined by its practices. The need to learn disciplinary discourse is facilitated by "examining the relationship between how communities participate in practices and their reifications of those practices." The writing class where popular science discourse is the central content provides an excellent platform for the examination of these community practices with the participation of community members helping to initiate student learners at the periphery into the community.

\section{CONCLUSION}

The aim of initiating science students into the academic literacy in this course is effected in a scaffolded manner through the use of popular science texts. There is the twofold aim of these texts providing the scientific content for engagement and yet with relative ease as compared to the use of professional science academic texts. The focus on coherence and clarity as key features to facilitate the communication of science content prioritises fundamentals of generally good effective communication but which is also central to science communication. This course resolves some of the challenges or tensions in balancing the need to help first-year students to develop general academic literacy as well as discipline specific skills. It also enables language teachers who are not science specialists to teach science discourse at a more comfortable level, where the demand for familiarity with science content is pitched at a lay audience level.

Siew Mei Wu is the Director of the Centre for English Language Communication, National University of Singapore. She is an editorial board member of the Asian Journal of the Scholarship of Teaching and Learning (AJSOTL).

Sze Han Lee is a PhD candidate in the Department of Pharmacy, National University of Singapore. He has tutored undergraduate pharmacokinetics modules, and has interest in statistics, metagenomics and metabolic profiling of diseases.

Eric Chun Yong Chan is a pharmaceutical scientist and an associate professor in the Department of Pharmacy, National University of Singapore. He is an editorial board member of the Asian Journal of the Scholarship of Teaching and Learning (AJSOTL).

\section{REFERENCES}

Afonso, A. S., \& Gilbert, J. K. (2013). The role of "popular" books in informal chemical education. International Journal of Science Education, Part B, 3(1), 77-99. http://dx.doi.org/10.1080/21548455.2012.733439

Arkoudis, S., Richardson, S., \& Baik, C. (2012). English Language Standards in Higher Education: From Entry to Exit. Camberwell: ACER Press.

Bamberg, B. (1983). What makes a text coherent? College Composition and Communication, 34(4), 417-429. http://dx.doi.org/10.2307/357898 
Blake, R. M., \& Pates, J. (2010). Embedding report writing workshops into an undergraduate Environmental Science module through a subject specialist and learning developer partnership. Journal of Learning Development in Higher Education, 2. https://journal.aldinhe.ac.uk/index.php/jldhe/article/view/43

Bond, T. G., \& Fox, C. M. (2007). Applying the Rasch Model: Fundamental Measurement in the Human Sciences (2nd ed.). Mahwah: Lawrence Erlbaum.

Bradley, D., Noonan, P., Nugent, H., \& Scales, B. (2008). Review of Australian Higher Education: Final report. Canberra: Commonwealth of Australia.http://apo.org.au/node/15776

Bullock, S. (2006). Building concepts through writing-to-learn in college physics classrooms. Ontario Action Researcher, 9(2), 1-8. http://eric.ed.gov/?id=EJ814916

Concha, S., \& Paratore, J. R. (2011). Local coherence in persuasive writing: An exploration of Chilean students' metalinguistic knowledge, writing process, and writing products. Written Communication, 28(1), 3469. http://dx.doi.org/10.1177/0741088310383383

Crossley, S. A., \& McNamara, D. S. (2010, August). Cohesion, coherence, and expert evaluations of writing proficiency. Paper presented at the 32nd annual conference of the Cognitive Science Society, Portland, OR.

Emerson, L., MacKay, B. R., MacKay, M. B., \& Funnell, K. A. (2006). A team of equals: Teaching writing in the sciences. Educational Action Research, 14(01), 65-81. http://dx.doi.org/10.1080/09650790600585335

Ganobcsik-Williams, L. (2006). Teaching Academic Writing in UK Higher Education: Theories, Practices and Models. London: Palgrave Macmillan.

Harris, A. (2016). Integrating written communication skills: Working towards a whole of course approach. Teaching in Higher Education, 21(3), 287-300. http://dx.doi.org/10.1080/13562517.2016.1138456 Hathaway, J. (2015). Developing that voice: Locating academic writing tuition in the mainstream of higher education. Teaching in Higher Education, 20(5), 506-517.

http://dx.doi.org/10.1080/13562517.2015.1026891

Hoey, M. (1991). Another perspective on coherence and cohesive harmony. In E. Ventola (Ed.), Trends in Linguistics, Studies and Monographs, Functional and Systemic Linguistics (385-414). Berlin: Mounton de Gruyter.

Hubball, H., \& Burt, H. (2007). Learning outcomes and program-level evaluation in a four-year undergraduate pharmacy curriculum. American Journal of Pharmaceutical Education, 71(5), 90. https://www.ncbi.nlm.nih.gov/pmc/articles/PMC2064888/

Hubball, H., \& Clarke, A. (2010). Diverse methodological approaches and considerations for SoTL in higher education. Canadian Journal for the Scholarship of Teaching and Learning, 1(1), Article 2. http://dx.doi.org/10.5206/cjsotl-rcacea.2010.1.2

Knoch, U. (2007). Little coherence, considerable strain for reader: A comparison between two rating scales for the assessment of coherence. Assessing Writing, 12(2), 108-128. https://doi.org/10.1016/j.asw.2007.07.002

Lea, M. R. (2004). Academic literacies: A pedagogy for course design. Studies in Higher Education, 29(6), 739-756. https://doi.org/10.1080/0307507042000287230

Lee, I. (2002). Helping students develop coherence in writing. Forum, 40(3), 32-39. http://eric.ed.gov/?id=EJ671646.

Linacre, J. M. (1994). Many-Facet Rasch Measurement. Chicago: MESA Press. https://www.insteps.com/a/LinacreMFRM-book.pdf

Lunz, M. E., \& Linacre, J. M. (1998). Measurement designs using multifacet Rasch modeling. In G.A. Marcoulides (Ed.), Modern Methods for Business Research (47-77). Mahwah: Lawrence Erlbaum.

Mercer-Mapstone, L., \& Kuchel, L. (2015). Core skills for effective science communication: a teaching resource for undergraduate science education. International Journal of Science Education, Part B, 1-21. http://dx.doi.org/10.1080/21548455.2015.1113573

Mubarak, Z. H., Hamzah, \& Radjab, D. (2013). An analysis of students' ability in building cohesion and coherence in argumentative essays written by the fourth year students of English Department at University of Bengkulu. English Language Teaching (ELT), 1(3). http://ejournal.unp.ac.id/index.php/elt/article/view/4592

Murray, N., \& Nallaya, S. (2014). Embedding academic literacies in university programme curricula: a case study. Studies in Higher Education, 41(7), 1-17. http://dx.doi.org/10.1080/03075079.2014.981150 
Parkinson, J., \& Adendorff, R. (2004). The use of popular science articles in teaching scientific literacy. English for Specific Purposes, 23(4), 379-396.http://dx.doi.org/10.1016/j.esp.2003.11.005

Rasch, G. (Ed.). (1992). Probabilistic Models for Some Intelligence and Attainment Tests. Chicago: University of Chicago Press.

Robles, M. M. (2012). Executive perceptions of the top 10 soft skills needed in today's workplace. Business Communication Quarterly, 75(4), 453-465. http://dx.doi.org/10.1177/1080569912460400

Soules, A., Nielsen, S., LeDuc, D., Inouye, C., Singley, J., Wildy, E., \& Seitz, J. (2014). Embedding multiple literacies into STEM curricula. College Teaching, 62(4), 121-128. http://dx.doi.org/10.1080/87567555.2014.935699

Sweet, A. P. (2000). Ten Proven Principles for Teaching Reading. Washington, DC: National Education Association. http://files.eric.ed.gov/fulltext/ED447441.pdf

Tapp, J. (2015). Framing the curriculum for participation: A Bernsteinian perspective on academic literacies. Teaching in Higher Education, 20(7), 711-722. http://eric.ed.gov/?id=EJ1073305

Thompson, C., Morton, J., \& Storch, N. (2013). Where from, who, why and how? A study of the use of sources by first year L2 university students. Journal of English for Academic Purposes, 12(2), 99-109. http://dx.doi.org/10.1016/j.jeap.2012.11.004

Todd, R. W., Thienpermpool, P., \& Keyuravong, S. (2004). Measuring the coherence of writing using topic-based analysis. Assessing Writing, 9(2), 85-104.http://dx.doi.org/10.1016/j.asw.2004.06.002

Wingate, U. (2012). Using academic literacies and genre-based models for academic writing instruction: A "literacy journey". Journal of English for Academic Purposes, 11(1), 26-37. http://dx.doi.org/10.1016/j.jeap.2011.11.006

Woodward-Kron, R. (2009). 'This means that ...": A linguistic perspective of writing and learning in a discipline. Journal of English for Academic Purposes, 8(3), 165-179. http://dx.doi.org/10.1016/j.jeap.2009.07.002

Zhang, S. Q., Chng, M., Ng, K. L., Wu, S. M., \& Chan, E. C. Y. (2017). Enhancing the communicative competence of science undergraduates through the use of popular science: A perspective from the students. Asian Journal of the Scholarship of Teaching and Learning, 7(2), 30-57. http://www.cdtl.nus.edu.sg/ajsotl/articles/v7n2 articles2.pdf

\section{APPENDICES}

Table S1. Rubric and scoring for pre- and post-essays under three major categories: content, organization and language

\begin{tabular}{|c|c|c|c|}
\hline MAJOR CATEGORY & & RUBRICS & SCORE \\
\hline Content & 4. & $\begin{array}{l}\text { Adequate background information provided throughout the } \\
\text { essay } \\
\text { Critical thinking reflected in the use of source ideas } \\
\text { Demonstration of ability to use information to develop the } \\
\text { relevant issue/ problem } \\
\text { Level of depth in arguments }\end{array}$ & $\begin{array}{l}5 \text { marks for } \\
\text { each item }\end{array}$ \\
\hline Organization & $\begin{array}{l}7 . \\
8 . \\
9 .\end{array}$ & $\begin{array}{l}\text { Introduction with position/thesis stated and a conclusion with } \\
\text { the position reinforced } \\
\text { Functions of source ideas discernible (contrastive, supporting, } \\
\text { illustrative, explanation) } \\
\text { Effective integration of source ideas and author's ideas } \\
\text { Logical progression of ideas between sentences } \\
\text { Connecting persuasive thread of ideas within and between } \\
\text { paragraphs (convergence with main position evident) }\end{array}$ & $\begin{array}{l}5 \text { marks for } \\
\text { each item }\end{array}$ \\
\hline Language & & $\begin{array}{l}\text { Accurate grammar } \\
\text { Well-formed variety of concise sentences } \\
\text { Vocabulary range and appropriate use } \\
\text { Academic tone }\end{array}$ & $\begin{array}{l}5 \text { marks for } \\
\text { each item }\end{array}$ \\
\hline
\end{tabular}


Table S2. Examples of pre-essay and post-essay from students

PRE-ESSAY
Example 1a
1) The world population is growing at a
staggering rate, a population of 6.6 billion now,
and an estimated increase to 9 billion people
by 2050 . Is this the start of a looming
ecological disaster?

2) Will there be enough food and water to sustain the surge in global demands?

3) Science has attempted to solve these world problems through the use of technology to advance the production of food and water.

4) In this exposition, I am going to discuss about aquaculture, a relatively new technology, and whether it is a sustainable method to meet the growing appetite of the world. (\#627)
POST-ESSAY

Example $1 \mathrm{~b}$

1) The world population is growing at a staggering rate; numbered at 6.6 billion currently, it is estimated to around 9 billion people by 2050 (Sachs, 2007).

2) Concerns about this population surge are raging, from the environmental impact posed by such a large number of people, to the availability of resources, especially food, to sustain everybody.

3) As usual, science has jumped onto the bandwagon to attempt to address these looming concerns through technology.

4) A relatively new technology called aquaculture-a water-based equivalent of agriculture-developed around the 1970s to increase supply of food, has received attention. $40 \%$ of the seafood we eat comes from aquaculture, and it has been growing $9 \%$ annually in economic output since 1975 (Stier, 2007).

5) Every seemingly good thing comes with a price, and although aquaculture may seem to be good on the surface, increasing food supply manifold, there exists caveats that we as consumers ought to be concerned about, mainly the environmental impacts and its sustainability.

6) Despite these valid concerns, aquaculture should be used as a sustainable method to meet the global demand for food.

7) This is because the benefit in terms of food supply one can get from aquaculture is simply too significant for us to give up on, and continual development and growth in the technology will soon iron out many of its existing flaws. (\#698)
Example 2a

1) Aquaculture defined as the 'farming of marine animals' has indeed improved the way in which aquatic food are obtained.

\section{Example 2b}

1) Aquaculture defined as the 'farming of marine animals' has improved the way in which aquatic foods are obtained. 
2) At the same time, it ensures that the ocean ecosystem is protected.

3) However, the claim that it is a sustainable way to meet the international demand for food is dubious for aquaculture comes with risks.

4) It is ironic that aquaculture which aims to provide a balance between the needs of the people and the ecosystem involves processes of actually endangering the ecosystem.

5) Although the demand for aquaculture is increasing, its popularity would eventually plummet and it would no longer be of use, an analogy of the ban of chlorofluorocarbons (CFCs). (\#657)
2) At the same time, it ensures that the ocean ecosystem is protected.

3) Aquaculture seems to provide the safe solution to our ever-growing global concerns of providing for the increasing global population such as shortage of natural resources and high cost.

4) However, opponents argue that aquaculture does not really bring the benefits that people thought it would.

5) Some even go on to argue that instead of solving the problems stated above, aquaculture exacerbates these problems.

6) Thus, the claim that it is a sustainable way to meet the international demand for food is dubious for aquaculture comes with risks.

7) Although the demand for aquaculture is increasing, its popularity would eventually plummet and it would no longer be of use.

8) An analogy can be found in the ban of chlorofluorocarbons (CFCs), illustrating the main point of this essay on why aquaculture would not be sustainable.

9) The other reasons underlying this argument include the unintended harmful effects of aquaculture on the ocean's ecosystem, the limitations of the positive effects of aquaculture and the lack of confidence of the future of aquaculture by those who support it. (\#704)

\section{Example 3b}

1) Pundits have criticised aquaculture for its underlying paradox of using more fish feed input than its food output.

2) For 10 types of fish most commonly farmed, an average of $1.9 \mathrm{~kg}$ of fish feed is required to produce $1 \mathrm{~kg}$ of farmed fish.

3) It is thus rather ironic that more wild fish supplies are required to produce farmed fish of less quantity.
1) Firstly, aquaculture provides the world population a safety net in food supply.

2) Aquaculture yields have been growing strong even as the global fish catch has peaked in the late 1980s (Sachs, 2007).

3) Its yield has increased about 25 times from 2 million metric tons in the 1950s to 50 million metric tons today. 
4) Also, mangrove swamps cleared to make way for aquaculture farms have resulted in the loss of habitat of many young fin-fish and shellfish which are caught as adults in offshore fisheries.

5) However, aquaculture is still a fairly unrefined technology as compared to its land cousin, agriculture which had its rapid development dubbed the "green revolution" since the 1950s.

6) I believe further research into this technology will stave off the ill-effects which comes with it.

7) Already, the amount of wild fish required to produce one unit of salmon was reduced by 25\% between 1997 and 2001.

8) This is the work of public funded research to evolve aquaculture technologies to face its challenges.

9) Even though the concerns of many regarding aquaculture is not unfounded, one must allow time for the technology to grow and improve. (\#691)
4) Sachs asserts rightly that this has enabled humans to continue fish even till this day.

5) Without aquaculture cushioning the impact of the increased fish consumption, fish prices may be much higher than the level it is today.

6) Pundits have often criticized aquaculture for its underlying paradox of using more fish feed input than its food output.

7) For 10 types of fish most commonly farmed, an average of $1.9 \mathrm{~kg}$ of fish feed is required to produce $1 \mathrm{~kg}$ of farmed fish.

8) Thus, they assert, it is rather ironic that more wild fish supplies are required to produce farmed fish of less quantity.

9) However, aquaculture is still a fairly unrefined technology as compared to its land cousin, agriculture, which had its rapid development dubbed the "green revolution" since the 1950s.

10) Further research into this technology will stave off the ill-effects which come with it.

11) Already, the amount of wild fish required to produce one unit of salmon was reduced by $25 \%$ between 1997 and 2001.

12) These are encouraging fruits of public-funded scientific research into the technology.

13) Aquaculture should not be abolished just because of some minor concerns because the benefits it provides far the costs. (\#892)

\section{Table S3. Sample tasks taken from course worksheets}

\begin{tabular}{|l|l|}
\hline $\begin{array}{l}\text { Section } 1 \\
\text { Exploring Ideas } \\
\text { in Popular } \\
\text { Science }\end{array}$ & $\begin{array}{l}\text { Discuss the following questions with your group members. A group will be randomly selected } \\
\text { to share their insights with the rest of the class. } \diamond \text { denotes more difficult questions that can be } \\
\text { discussed after the last question and when there is time. }\end{array}$ \\
1. $\begin{array}{l}\text { From geocentric to heliocentric to the big bang models of the universe. What } \\
\text { implications do you draw from these for learning and doing science? }\end{array}$ \\
2. Hawking believes that our picture of the universe will one day be complete. What \\
grounds his belief? How convincing is his reasoning? \\
3. As Hawking notes, a theory "exists only in our minds and does not have any other \\
reality." Does this reduce the value of scientific research?
\end{tabular}




\begin{tabular}{|c|c|c|}
\hline & \multicolumn{2}{|c|}{$\begin{array}{l}\text { 4. Why does Hawking write that "the search for the ultimate theory of the universe seems } \\
\text { difficult to justify on practical grounds" (p. 13)? How did this statement affect you as a } \\
\text { reader? } \\
\text { 5. "But there is a fundamental paradox in the search for such a complete unified theory" } \\
\text { (p.12). Articulate this paradox, and explain the point that Hawking is making here. }\end{array}$} \\
\hline $\begin{array}{l}\text { Section } 2 \\
\text { Exploring } \\
\text { Science } \\
\text { Communication }\end{array}$ & \multicolumn{2}{|c|}{$\begin{array}{l}\text { Discuss the following questions with your group members and then share your insights with the } \\
\text { rest of the class. Make suitable references to your reading to support your answer. } \\
\text { 6. How would you describe Hawking's style of writing in this chapter? Discuss the impact } \\
\text { of his stylistic choice on readers. To do this, consider the following: } \\
\text { - Would you regard his chapter as a narrative, description, or argument? } \\
\text { - How effective is his choice? What effects on the reader are achieved? } \\
\text { - What is gained or lost as a result of his choice? }\end{array}$} \\
\hline \multirow{6}{*}{$\begin{array}{l}\text { Section } 3 \\
\text { Analysing } \\
\text { explanation } \\
\text { strategies and } \\
\text { clarification } \\
\text { techniques }\end{array}$} & \multicolumn{2}{|c|}{$\begin{array}{l}\text { 1. Compare how the problem of hybridization is explained in the new story (Buchen, } \\
\text { 2009) and its source article (Tanaka et al., 2009). Describe the changes in vocabulary, } \\
\text { syntax and text that occur, and discuss the effects of these changes on readers. }\end{array}$} \\
\hline & From Tanaka et al. (2009) & From Buchen (2009) \\
\hline & $\begin{array}{l}\text { In Magicicada, the fitness costs of } \\
\text { hybridization may be elevated by } \\
\text { predation; periodical cicadas suffer } \\
\text { heavy mortality at low population } \\
\text { densities because they rely on mass } \\
\text { numbers and a strategy of 'predator } \\
\text { satiation' for survival }(9,10) \text {. (p. } \\
8975)\end{array}$ & $\begin{array}{l}\text { This is a problem, Cooley said, because } \\
\text { periodical cicadas find strength in numbers. } \\
\text { They're easy to catch and don't bite or sting, } \\
\text { so they easily become snacks for hungry } \\
\text { predators. But by buzzing around with } \\
\text { hundreds of thousands of other cicadas, the } \\
\text { probability of any one being eaten is close to } \\
\text { zero. (Section 6) }\end{array}$ \\
\hline & \multicolumn{2}{|c|}{$\begin{array}{l}\text { 2. Compare how the limitations of the study is explained in the new story (Buchen, } \\
\text { 2009) and its source article (Tanaka et al., 2009). Describe the changes in vocabulary, } \\
\text { syntax and text that occur, and discuss the effects of these changes on readers. }\end{array}$} \\
\hline & From Tanaka et al. (2009) & From Buchen (2009) \\
\hline & $\begin{array}{l}\text { The most unrealistic aspect of our } \\
\text { model is that it presupposes } \\
\text { geographic overlap of periodical life } \\
\text { cycles; Among the modern-day } \\
\text { periodical cicada broods, such life } \\
\text { cycle overlap is virtually nonexistent } \\
\text { (1). (p. } 8977 \text { ) }\end{array}$ & $\begin{array}{l}\text { Cooley acknowledges the model made a } \\
\text { number of assumptions, as the difficulty of } \\
\text { studying cicadas leaves many mysteries } \\
\text { around their biology and evolution. For } \\
\text { example, it isn't known whether hybridization } \\
\text { actually produces offspring with intermediate } \\
\text { lifecycles. And currently, the } 13 \text {-year and } 17- \\
\text { year broods' habitats do not overlap, so they } \\
\text { don't have a chance to interbreed in present } \\
\text { day-though their distribution has likely } \\
\text { changed since they first diverged. (Section } \\
10 \text { ) }\end{array}$ \\
\hline
\end{tabular}


Figure S1. Frequency distribution histogram of students' pre- and post-course scores.

\section{Histogram of overall}

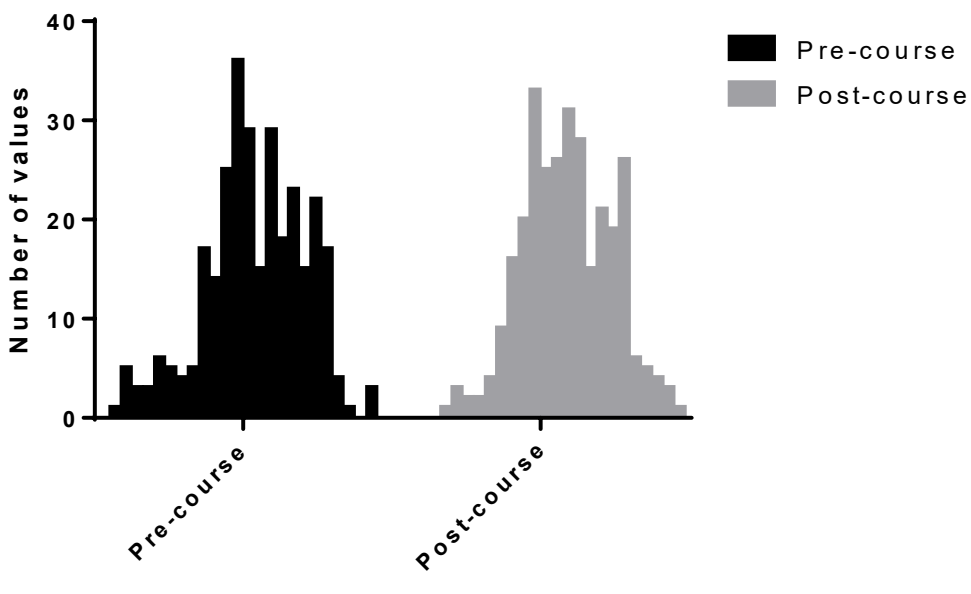

Bin Center

The pre-course score showed slight negative skew and failed the D'Agostino \& Pearson normality test $\left(\mathrm{K}^{2}=7.148, \mathrm{p}=0.0280\right)$, while the post-course score showed slight asymmetry but passed the normality test $\left(\mathrm{K}^{2}=1.999, \mathrm{p}=0.3680\right)$.

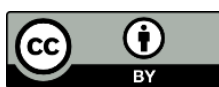

Copyright for the content of articles published in Teaching \& Learning Inquiry resides with the authors, and copyright for the publication layout resides with the journal. These copyright holders have agreed that this article should be available on open access under a Creative Commons Attribution License 4.0 International (https://creativecommons.org/licenses/by/4.0). The only constraint on reproduction and distribution, and the only role for copyright in this domain, should be to give authors control over the integrity of their work and the right to be properly acknowledged and cited, and to cite Teaching \& Learning Inquiry as the original place of publication. Readers are free to share these materials-as long as appropriate credit is given, a link to the license is provided, and any changes are indicated. 